\title{
Próba prognozowania rocznej temperatury powietrza w Szczecinie za pomocą wyrównywania wykładniczego
}

\author{
An attempt at forecasting annual temperature in Szczecin city \\ with the aid of exponential smoothing
}

\author{
ANDRZEJ GREGORCZYK, BOŻENA MICHALSKA \\ Zachodniopomorski Uniwersytet Technologiczny, 71-459 Szczecin, ul. Pawła VI 3; \\ andrzej.gregorczyk@zut.edu.pl bozena.michalska@zut.edu.pl
}

\begin{abstract}
Zarys treści. Celem pracy było zastosowanie metody wyrównywania wykładniczego do opisu zmian średniej rocznej temperatury powietrza w Szczecinie w latach 1949-2008, a także próba predykcji badanej cechy na następne dziesięciolecie. Badaniom poddano szereg czasowy rocznej temperatury powietrza, obliczonej z wartości miesięcznych zebranych ze stacji meteorologicznej w Szczecinie Dąbiu. Zastosowano metodę wyrównywania wykładniczego Browna, w której użyto modelu addytywnego oraz multiplikatywnego, z trendem liniowym i 8-letnim składnikiem okresowym. Metoda wyrównania wykładniczego okazała się skuteczna w odniesieniu do predykcji średniej temperatury powietrza w badanym 60-leciu. Zdolności prognostyczne obu modeli wyrównywania wykładniczego są zbliżone i obarczone około 6\% błędem względnym.

Słowa kluczowe: temperatura powietrza, szereg czasowy, wyrównywanie wykładnicze, model addytywny, model multiplikatywny.
\end{abstract}

\section{Wstęp}

Podstawowy element klimatu, jakim jest temperatura powietrza, ulega naturalnym zmianom w czasie - wahaniom dobowym, sezonowym, rocznym i wieloletnim - a także zmianom antropogenicznym, wynikającym ze wzrostu zawartości pyłu w atmosferze i gazów szklarniowych lub innych form działalności człowieka (Boryczka i Stopa-Boryczka, 2004).

Cykliczność naturalna zmian klimatu wywołana jest ruchem obrotowym Ziemi, ruchem Ziemi wokół Słońca oraz zmianą aktywności Słońca (Boryczka, 2001), zaś zmiany klimatu związane z czynnikiem antropogenicznym cechuje stała tendencja, czyli trend liniowy (Michalska, 2009; Miler i Miler, 2000). W ogólności powyższe zjawiska należy traktować - w ujęciu statystycznym - jako niestacjonarny proces stochastyczny (Montgomery i inni, 1990; Ripley, 2006). 
Wartość obserwowanej cechy (na przykład średniej temperatury rocznej) w okresach wieloletnich rozpatruje się jako funkcję zmiennej czasowej $y(t)$ :

$$
y(t)=M+T+C+\varepsilon
$$

gdzie:

$M$ - przeciętny poziom zjawiska,

$T$ - trend,

C - cykl długookresowy,

$\varepsilon-$ składnik losowy.

Analiza długich serii pomiarowych może być podstawą do prognozowania statystycznego, po uprzedniej dekompozycji szeregu czasowego na trend, okresowość i tzw. reszty (Luszniewicz i Słaby, 2003).

W badaniach wieloletnich zmian czynników klimatycznych dużą użyteczność jako narzędzie prognoz krótko- i średnioterminowych zyskała metoda wyrównywania wykładniczego Browna (Brown, 1963; Gardner, 1985). W tej metodzie szereg czasowy jest traktowany całościowo, jednak pośrednio można uwzględniać także składnik okresowy czy trend danego zjawiska. Proste wyrównywanie polega na obliczaniu średniej ruchomej, w której starsze obserwacje mają przypisane wykładniczo mniejsze wagi niż dane bieżące. Rekurencyjny wzór takiej procedury ma postać:

$$
\hat{y}_{t}=\alpha y_{t}+(1-\alpha) \hat{y}_{t-1}
$$

gdzie:

$\hat{y}_{t}$ - wartości estymowane (wygładzone),

$y_{t}$ - wartości obserwowane,

$t$ - czas,

$\alpha$ - parametr wygładzania, $\alpha \in<0,1>$.

Gdy analizowany szereg zawiera składnik okresowy i kierunek rozwoju badanego procesu jest wyraźny, stosuje się model wygładzania wykładniczego, zawierający parametr wyrównania sezonowego i parametr trendu. Parametry te przybierają wartości między 0 i 1. W zależności od charakteru okresowości można zbudować model addytywny (w którym wahania sezonowe są jednostajne) oraz model multiplikatywny (w którym amplituda wahań jest zmienna w zależności od trendu).

W modelu addytywnym wartości prognozowane $y_{p}(t)$ obliczane są według wzoru:

$$
y_{p}(t)=\hat{y}_{t}+I_{t-T}
$$

w modelu multiplikatywym zaś według formuły

$$
y_{p}(t)=\hat{y}_{t} \cdot I_{t-T}
$$

gdzie $I_{t-T}$ oznacza wygładzony składnik (czynnik) sezonowy w czasie $t$ minus $T$ ( $T$ - okres wahań). 
Celem pracy było zastosowanie metody wyrównywania wykładniczego (w dwóch wariantach) do opisu zmian średniej rocznej temperatury powietrza w Szczecinie w latach 1949-2008, a także próba predykcji badanej cechy na następne dziesięciolecie.

\section{Zakres badań i metody}

Badaniom poddano szereg czasowy średniej rocznej temperatury powietrza, obliczonej z wartości miesięcznych, zebranych ze stacji meteorologicznej w Szczecinie Dąbiu (53²4', 14³7', 1 m npm.) za lata 1949-2008. W badaniach zastosowano metodę wyrównywania wykładniczego, dostępną w pakiecie Statistica 9. Kierując się wstępnymi wynikami analizy tego szeregu czasowego temperatury, użyto modelu addytywnego i multiplikatywnego z trendem liniowym i 8-letnim składnikiem okresowym.

Adekwatność procedury wyrównywania wykładniczego szeregu czasowego oceniono na podstawie wielkości błędów, popełnianych w poszczególnych wariantach wygładzania danych pierwotnych (Musiał i Rojek, 2001; Podgórski, 1996). Jako miary bezwzględnej dobroci dopasowania użyto średniego błędu kwadratowego (mean square error, MSE):

$$
M S E=\frac{1}{n} \sum_{i=1}^{n}\left(y_{i}-\hat{y}\right)^{2}
$$

oraz - jako wskaźnika względnego - średniego absolutnego błędu procentowego (mean absolute percentage error, MAPE):

$$
\text { MAPE }=\frac{1}{n} \sum_{i=1}^{n} \frac{\left|y_{i}-\hat{y}_{i}\right|}{y_{i}} \cdot 100 \%
$$

gdzie $n$ - długość szeregu.

Średni błąd kwadratowy odpowiada średniej wartości kwadratu reszt, a średni absolutny błąd procentowy informuje, o ile procent przeciętna wartość estymowana odchyla się od wartości rzeczywistej.

\section{Wyniki i dyskusja}

Przeprowadzone obliczenia testu normalności Shapiro-Wilka (prawdopodobieństwo testowe $p=0,146)$ nie dały podstaw do odrzucenia hipotezy o rozkładzie normalnym analizowanej cechy na poziomie istotności 0,05 . Średnia roczna temperatura w badanym 60 -leciu wyniosła $8,68^{\circ} \mathrm{C}$, mediana była równa $8,74^{\circ} \mathrm{C}$, a odchylenie standardowe $0,87^{\circ} \mathrm{C}$. Stwierdzono także występowanie dodatniego trendu liniowego o współczynniku regresji $0,024^{\circ} \mathrm{C} \cdot \mathrm{rok}^{-1}$. 
Przebieg zmian analizowanego elementu klimatycznego w latach 1949-2018 (wartości rzeczywiste tylko do 2008 r.) przedstawiono na rycinach 1 i 2, uwzględniających oba zastosowane modele wyrównywania wykładniczego. W modelu addytywnym (ryc. 1) szereg czasowy wykazuje, oprócz dodatniego trendu, stałe wahania okresowe temperatury. W modelu multiplikatywnym (ryc. 2) wielkość wahań temperatury rośnie wraz z trendem. Najniższą średnią temperaturę roczną odnotowano w roku $1956\left(7,01^{\circ} \mathrm{C}\right)$, a najwyższą $\left(10,28^{\circ} \mathrm{C}\right)-\mathrm{w} 2007$.

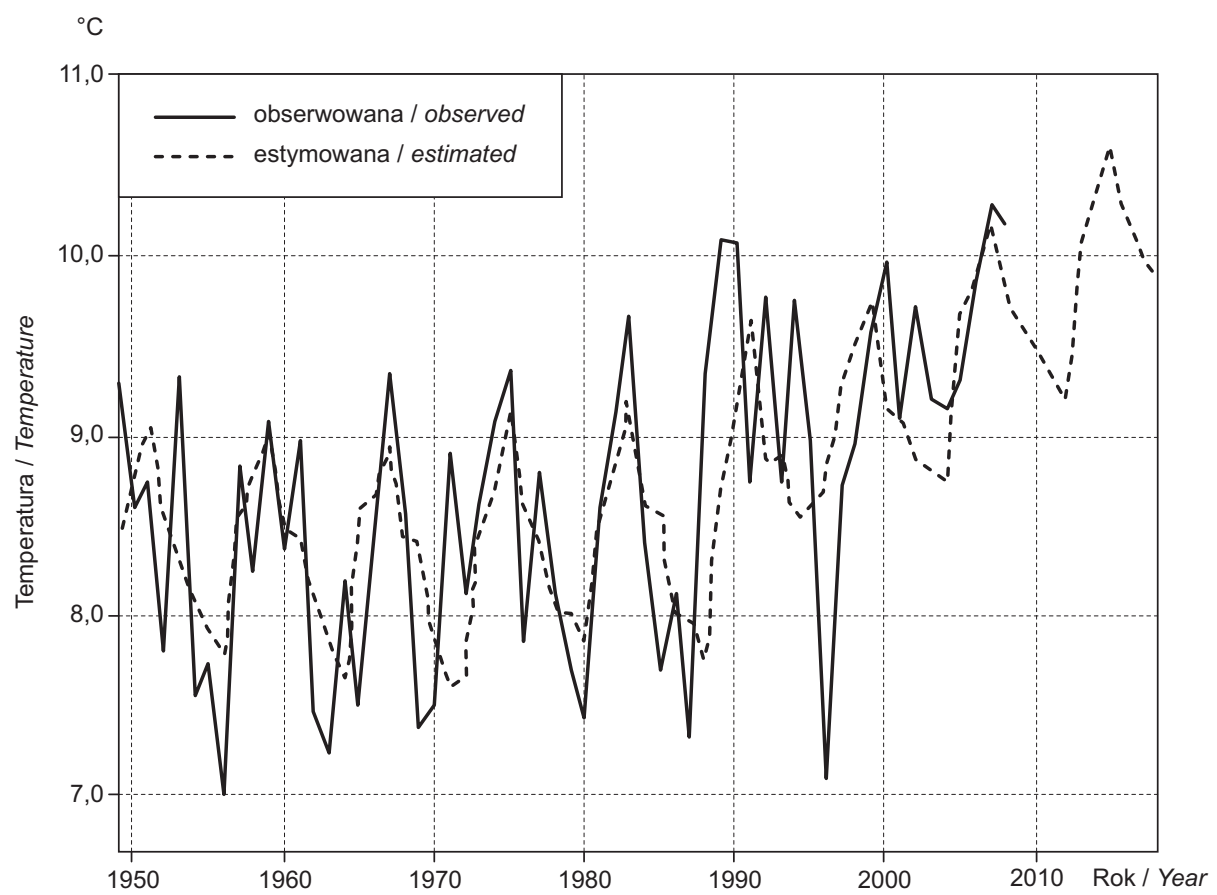

Ryc. 1. Obserwowane i estymowane zmiany średniej rocznej temperatury powietrza w Szczecinie w latach 1949-2018 (model addytywny)

The observed and estimated changes in mean annual air temperature in Szczecin over the years 1949-2018 (additive model)

Tabela 1 zawiera obserwowane i wygładzone - według modelu addytywnego i multiplikatywnego - wartości temperatury powietrza w Szczecinie od 2004 r., a także wartości prognozowane na lata 2009-2018.

Analizując ryciny 1 i 2 oraz tabelę 1 można zauważyć dobre dopasowanie danych oryginalnych w latach 1949-2008 do wartości estymowanych. Średnie błędy kwadratowe MSE są zbliżone i wynoszą dla modelu addytywnego $0,45\left({ }^{\circ} \mathrm{C}\right)^{2}$, a dla modelu multiplikatywnego $-0,41\left({ }^{\circ} \mathrm{C}\right)^{2}$. Średni absolutny błąd 
procentowy MAPE jest równy odpowiednio 6,31\% i 6,06\%, co może świadczyć o dobrej jakości prognozy.

W roku 2009 średnia rzeczywista temperatura powietrza wyniosła $9,30^{\circ} \mathrm{C}$, a więc różniła się od wartości estymowanej za pomocą modelu addytywnego tylko o 3,2\% i multiplikatywnego o 3,0\%.

Obserwowany dodatni trend liniowy oraz około 8-letni cykl zmian badanego zjawiska pozwala przypuszczać, że w roku 2012 wystąpi minimum lokalne temperatury powietrza (około $9,1-9,2^{\circ} \mathrm{C}$ ), natomiast w roku 2015 - maksimum lokalne $\left(10,6-10,8^{\circ} \mathrm{C}\right)$.

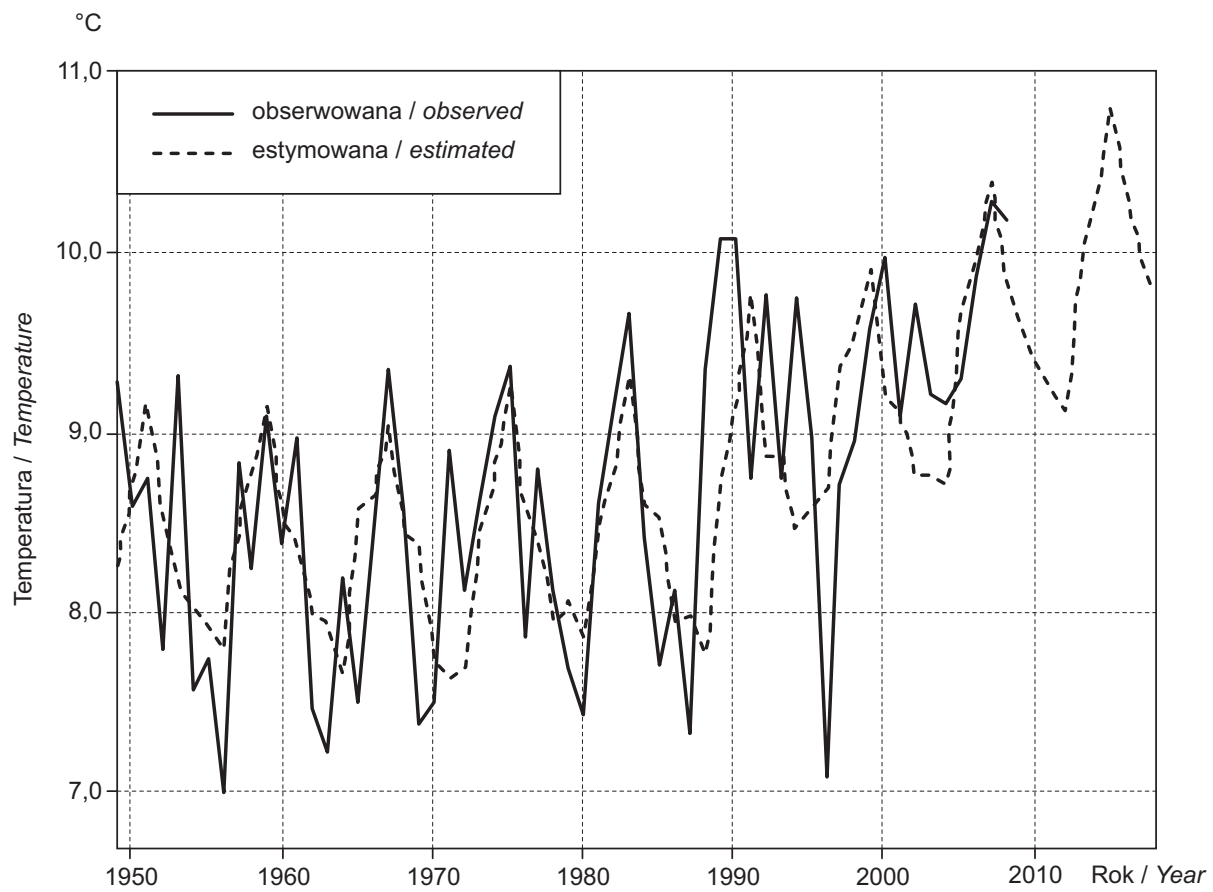

Ryc. 2. Obserwowane i estymowane zmiany średniej rocznej temperatury powietrza w Szczecinie w latach 1949-2018 (model multiplikatywny)

The observed and estimated changes in mean annual air temperature in Szczecin over the years 1949-2018 (multiplicative model)

M. Miętus (1996) na podstawie długoletniej serii obserwacyjnej (lata 18361990) oszacował wzrost średniej rocznej temperatury powietrza w rejonie polskiego wybrzeża Bałtyku na $0,7^{\circ} \mathrm{C}$ na 100 lat, wskazując na osłabienie tego wzrostu od połowy lat 1920. Z badań B. Michalskiej (2009) nad zmiennością temperatury powietrza na Pomorzu wynika, że w latach 1951-2005 średnia roczna temperatura wzrastała, w zależności od regionu, w tempie od 0,1 do $0,3^{\circ} \mathrm{C}$ na 10 lat. 
E. Musiał i inni (2004), analizując 38-letnią serię średnich rocznych temperatur powietrza (za lata 1964-2001) w stacji meteorologicznej Wrocław Swojec, stwierdzili ocieplenie na tym obszarze, które opisuje istotny statystycznie rosnący trend o wzroście $0,31^{\circ} \mathrm{C}$ na 10 lat.

Tabela 1. Obserwowane i estymowane, według dwóch modeli wyrównywania wykładniczego, wartości temperatury powietrza $\left({ }^{\circ} \mathrm{C}\right)$ w Szczecinie w latach $2004-2018$

2004-2018 observed and estimated values for air temperature $\left({ }^{\circ} \mathrm{C}\right)$ in line with the two models of exponential smoothing

\begin{tabular}{|c|c|c|c|}
\hline \multirow{2}{*}{$\begin{array}{l}\text { Rok } \\
\text { Year }\end{array}$} & \multirow{2}{*}{$\begin{array}{c}\text { Temperatura } \\
\text { obserwowana } \\
\text { Observed } \\
\text { temperature }\end{array}$} & \multicolumn{2}{|c|}{$\begin{array}{c}\text { Temperatura estymowana } \\
\text { Estimated temperature }\end{array}$} \\
\hline & & $\begin{array}{l}\text { model addytywny } \\
\text { additive model }\end{array}$ & $\begin{array}{c}\text { model multiplikatywny } \\
\text { multiplicative model }\end{array}$ \\
\hline 2004 & 9,15 & 8,73 & 8,70 \\
\hline 2005 & 9,30 & 9,66 & 9,70 \\
\hline 2006 & 9,86 & 9,90 & 9,98 \\
\hline 2007 & 10,28 & 10,18 & 10,38 \\
\hline 2008 & 10,18 & 9,76 & 9,80 \\
\hline 2009 & $\mathrm{x}$ & 9,60 & 9,58 \\
\hline 2010 & $\mathrm{x}$ & 9,47 & 9,36 \\
\hline 2011 & $\mathrm{x}$ & 9,28 & 9,22 \\
\hline 2012 & $\mathrm{x}$ & 9,19 & 9,11 \\
\hline 2013 & $\mathrm{x}$ & 10,01 & 10,01 \\
\hline 2014 & $\mathrm{x}$ & 10,32 & 10,37 \\
\hline 2015 & $\mathrm{x}$ & 10,62 & 10,80 \\
\hline 2016 & $\mathrm{x}$ & 10,23 & 10,26 \\
\hline 2017 & $\mathrm{x}$ & 9,98 & 9,95 \\
\hline 2018 & $\mathrm{x}$ & 9,85 & 9,73 \\
\hline
\end{tabular}

J. Boryczka i M. Stopa-Boryczka (2004) udowodnili wahania temperatury powietrza w Warszawie o okresie 8,3 lat. Z kolei 7,7-letnią cykliczność temperatury powietrza w Polsce w latach 1951-1990 stwierdziła E. Żmudzka (1995), a także M. Miętus (1996) dla polskiego wybrzeża Bałtyku i H. Lorenc (1993) dla ośrodków w Polsce o ograniczonej antropogeniczności. Podobną cykliczność wykazuje też temperatura powietrza w Poznaniu w latach 1848-1995 (Miler i Miler, 2000). Z powyższych rozważań wynika, że przyjęte w niniejszej pracy 
trend liniowy i cykliczność temperatury powietrza w Szczecinie, w 60-letnim przedziale czasowym, nie odbiegają znacząco od wartości charakteryzujących inne regiony kraju, tym bardziej że A. Gregorczyk i B. Michalska (2010) udowodnili 8,6-letnią cykliczność temperatury powietrza w Szczecinie w latach 1949-2008.

E. Musiał i inni $(2001,2004)$ zastosowali metodę wyrównywania wykładniczego Wintera do opisu i prognozowania temperatury powietrza w okolicach Wrocławia. Model Wintera, uwzględniający liniowy trend, wahania sezonowe oraz wahania losowe dla średniej miesięcznej temperatury powietrza - w okresie 1964-2001 - został dopasowany z błędem względnym równym 6,02\%. Podobną wartość średniego absolutnego błędu procentowego (MAPE) uzyskano w niniejszej pracy.

Przewidywanie przyszłych realizacji wartości zmiennych losowych - na przykład temperatury powietrza - oparte jest na wielu założeniach, a mianowicie że w okresie prognozy nie ulegną istotnej zmianie tendencja rozwojowa, wahania okresowe i mechanizmy przyczynowo-skutkowe o charakterze losowym (Luszniewicz i Słaby, 2003; Montgomery i inni, 1990). Są to założenia często słabo sprawdzalne i zawsze mające wpływ na wynik predykcji. Realne prognozowanie zjawisk meteorologicznych nie powinno opierać się wyłącznie na metodach statystycznych, lecz wymaga także zespołowej wiedzy interdyscyplinarnej i stosowania różnych scenariuszy rozwoju.

\section{Wnioski}

Metoda wyrównywania wykładniczego Browna okazała się skuteczna w odniesieniu do predykcji średniej temperatury powietrza w okolicach Szczecina, w latach 1949-2008.

Zdolności prognostyczne obu modeli wyrównywania wykładniczego (addytywnego i multiplikatywnego) są zbliżone i obarczone około 6\% błędem względnym.

\section{Piśmiennictwo}

Boryczka J., 2001, Klimat Ziemi, przeszłość, teraźniejszość, przyszłość, Prace i Studia Geograficzne, UW, Warszawa, 29, s. 55-71.

Boryczka J., Stopa-Boryczka M., 2004, Cykliczne wahania temperatury i opadów w Polsce w XIX-XXI wieku, Acta Agrophysica, 3, 1, s. 21-33.

Brown R.G., 1963, Smoothing, Forecasting and Prediction of Discrete Time Series, Englewood Cliffs, Prentice-Hall, London.

Gardner E.S., 1985, Exponential smoothing: The state of the art, Journal of Forecasting, 4, s. $1-28$. 
Gregorczyk A., Michalska B., 2011, Zmienność temperatury powietrza w Szczecinie w latach 1949-2008, Acta Agrophysica, 17, 2, s. 301-309.

Lorenc H., 1993, Symptomy zmian klimatu w strefach ograniczonych wpływów antropogennych, Materiały Badawcze IMGW, Warszawa, Seria Meteorologia, 19.

Luszniewicz A., Słaby T., 2003, Statystyka z pakietem komputerowym Statistica PL, C.H. Beck, Warszawa.

Michalska B., 2009, Variability of air temperature in north western Poland, [w:] Z. Szwejkowski (red.), Environmental Aspects of Climate Change, University of Warmia and Mazury, Olsztyn, s. 89-107.

Miętus M., 1996, Zmienność temperatury i opadów w rejonie polskiego wybrzeża Bałtyku $i$ jej spodziewany przebieg do roku 2030, Materiały Badawcze IMGW, Warszawa, Seria Meteorologia, 26.

Miler A. T., Miler M., 2000, Trendy i okresowości zmian temperatury oraz opadów dla Poznania w latach 1848-2000, Zeszyty Naukowe Politechniki Koszalińskiej, Inżynieria Środowiska, 22, s. 945-956.

Montgomery D.C., Johnson L.A., Gardiner J.S., 1990, Forecasting and Time Series Analysis, McGraw-Hill, New York.

Musiał E., Gąsiorek E., Rojek M., 2004, Zmienność temperatury powietrza w obserwatorium Wrocław-Swojec w latach 1964-2001, Acta Agrophysica, 3, 2, s. 333-342.

Musiał E., Rojek M., 2001, Prognozowanie temperatury powietrza dla stacji Swojec na podstawie pomiarów w okresie 1964-2000, Przegląd Naukowy Inżynieria i Kształtowanie Środowiska, 21, s. 171-178.

Podgórski J., 1996, Statystyka z komputerem, ZNI Mikom, Warszawa.

Ripley B., 2006, Stochastic Simulation, John Wiley, New York.

Żmudzka E., 1995, Tendencje i cykle zmian temperatury powietrza w Polsce $w$ latach 1951-1990, Przegląd Geofizyczny, 40, 2, s. 129-139.

[Wpłynęło: grudzień 2010; poprawiono: kwiecień 2011 r.]

\section{ANDRZEJ GREGORCZYK, BOŻENA MICHALSKA}

\section{AN ATTEMPT AT FORECASTING ANNUAL TEMPERATURE IN SZCZECIN CITY WITH THE AID OF EXPONENTIAL SMOOTHING}

The study presented here includes a time series for mean annual air temperatures calculated from monthly values gathered at the Szczecin Dąbie meteorological station (53⒉', 14³7', $1 \mathrm{~m}$ above sea level) over the years 1949-2008. It employs the exponential smoothing method, available in the Statistica 9 packet. On the basis of the initial results from the analysis of this temperature time series, additive and multiplicative models with a linear trend and an eight-year seasonal component were used, before the adequacy of the procedure applied in exponential smoothing was assessed for the quantity of errors made in particular variants for the smoothing of the initial data. A mean square error (MSE) was used as an absolute goodness-of-fit measure, while a mean absolute percentage error (MAPE) was applied and as an absolute index. The calculations of the test of normality carried out did not offer a basis for rejecting the hypothesis of a normal distribution of the analyzed feature at a significance level of 0.05 . The 
mean annual temperature in the studied period of 60 years amounted to $8.68^{\circ} \mathrm{C}$, the median was equal to $8.74^{\circ} \mathrm{C}$, while the standard deviation was $0.87^{\circ} \mathrm{C}$. It was also shown that there was a positive linear trend for which the regression coefficient was equal to $0.024^{\circ} \mathrm{C} \cdot$ year $^{-1}$. A good fit between the original data and the estimated values was observed. Mean square errors MSE were approximate and they equal $0.45\left({ }^{\circ} \mathrm{C}\right)^{2}$ for the additive model and $0.41\left({ }^{\circ} \mathrm{C}\right)^{2}$ for the multiplicative model. The mean absolute percentage errors (MAPE) amount respectively to $6.31 \%$ and $6.06 \%$, and this may prove a good forecast quality. The observed positive linear trend and a c. eight-year cycle of changes of the studied phenomenon allow us to presume that 2012 may bring a local minimum temperature of air (approx. $9.1-9.2^{\circ} \mathrm{C}$ ), whereas in 2015 there will be a local maximum temperature (approx. 10.6-10.8 ${ }^{\circ} \mathrm{C}$ ). On the whole, the Brown exponential smoothing method emerges as effective when it comes to predicting mean temperature of the air in the surroundings of Szczecin over the years 1949-2008, as well as the prognostic abilities of the two models of the exponential smoothing method (additive and multiplicative) are approximate and encumbered with a c. 6\% relative error. 
http://rcin.org.pl 